\title{
A strategic policy scenario analysis framework for the sustainable tourist development of peripheral small island areas - the case of Lefkada-Greece Island
}

\author{
Anastasia Stratigea $^{1} \cdot$ Vicky Katsoni $^{2}$
}

Received: 9 March 2015 / Accepted: 7 April 2015 / Published online: 18 April 2015

(C) The Author(s) 2015. This article is published with open access at Springerlink.com

\begin{abstract}
The focus of the present paper is on the development of a methodological framework for guiding strategic decision-making towards the sustainable future development of peripheral small island regions, constituting distinct examples of lagging behind regions at a European scale. This will be implemented to a specific peripheral small island region, the island of Lefkada-Greece, seeking the integrated development of the island with emphasis on the sustainable exploitation of local tourist assets. The proposed framework is built upon the exploration of both the external and internal environment of such regions as well as the use of foresight and participatory evaluation tools. The study of the external environment aims at shedding light on the potential developments of the 'decision environment', within which policy making has to take place; and is framed by policy developments and tourist market trends ranging from the global to the national/ regional level. The analysis of the internal environment aims at gathering knowledge concerning the specific environmental, economic and social context of the study region, where the strategic planning exercise is addressed. Information gathered on potential developments of the external environment are used to inform the structuring and evaluation of sustainable tourist development scenarios in order to conclude with the
\end{abstract}

Anastasia Stratigea

stratige@central.ntua.gr

1 Department of Geography and Regional Planning, School of Rural and Surveying Engineering, National Technical University of Athens (NTUA), Heroon Polytechniou 9, Zographou Campus, 15780 Athens, Greece

2 Faculty of Management and Economics, Department of Business Administration, Division of Tourism Administration, Athens Technological Educational Institute, Milou 1, Aigaleo, 12210 Athens, Greece most prevalent future perspective for the specific region, taking into consideration the local preferences and values in a participatory evaluation context. Finally, some conclusions are drawn, based on the experience gained from the application of the proposed methodological approach and the results obtained from the specific case study.

Keywords Peripheral small island regions $\cdot$ Sustainable tourist development - Alternative tourism - Spatial planning . Scenarios $\cdot$ Participatory evaluation $\cdot$ Policy

\section{Introduction}

Sustainable tourist development has nowadays been set at the epicentre of local policies in tourist developed areas, in an effort to both reap the economic benefits of tourist development but also manage local resources in such a way that cultural integrity, essential ecological processes, biological diversity and life support systems are maintained. In this respect, the present needs of tourists and host communities are met, whilst the potential of future generations to satisfy their needs is also protected.

The goal of sustainable tourist development is nowadays broadly advocated by developments in the demand and supply side, as well as policy decisions at the destinations' level. More specifically, sustainable tourist destinations have been largely motivated by the demand side, where well informed and environmentally conscious consumers exhibit a steadily increasing preference in environmentally-committed tourist destinations [1,2]; and an increasing interest in purchasing environmentally-friendly tourist products and services. In response to consumers' preferences, the supply side (tourist business sector) has made considerable effort to take advantage of systems and procedures that can incorporate 
sustainability objectives in core management functions and identify measures for their implementation [1, 2], placing thus environmental concern and rational use of resources, both natural and human, at the heart of their production processes [3-6]. Finally, decision makers have placed sustainability objectives at the core of their policies for sustainable tourist destinations, in order long term development perspectives on behalf of both local population and visitors to be supported; while regionalization of decision-making processes of the last decades and the increasing power of local policy making bodies [7] has increased capabilities for inclusive approaches in planning and implementing sustainable local tourist development paths. These policies constitute the outcome of the realization that support of sustainable tourism has the potential to boost the sector's contribution to economic growth, development and job creation, while simultaneously addressing the major environmental challenges of the times [8].

Peripheral small island regions are nowadays perceived as attractive tourist destinations at a global scale, while the number of such regions that are making consistent efforts to enter the tourist market is steadily increasing [9]. Although small island regions are exhibiting certain weaknesses as to their development perspectives in comparison to hinterland [10], experience shows that an important part of Small Island Tourism Economies (SITE) [11] are successful from an economic point of view. This is largely based on their exceptional natural and cultural resources, whose exploitation forms the core of policy decisions for solving small islands' challenging development problems [12]. These policies can provide a solution for reaching a level of economic prosperity, but at the same time they can also cause severe problems by placing a rather high burden on environmental and social aspects. Also, they result in a certain specialization of small islands' open economies, which can expose them to severe risks emerging from the external environment, such as economic and political instability, climate change impacts, high dependence on volatile demand, etc., threatening thus the achievement of sustainable development paths. Giannoni and Maupetuis [11] state that these policies, although effective in a short term, they fail to ensure flourishing of small islands in a long term perspective, since they do not adequately focus on the core aspect of such a development, i.e. the natural resources being at stake.

Coping with risks inherent to unsustainable development paths of small island regions, calls for a more integrated development approach, seeking a low ecological footprint tourist development pattern and a better integration of the tourist sector in the local economic structure for a 'fair' benefit sharing by the local society. Moreover, it calls for a rather long term approach for meeting present but also future generations' needs. These requests are intensifying the interest in foresight initiatives at the regional/local level, placing foresight exercises at the core of decision-making processes where, by taking advantage of the strengths and opportunities of such peripheral small island regions in a sustainable development context, more knowledgeable, integrated, coherent and well structured policies can be implemented for creating a more qualitative and hopeful future for their population.

Based on the above discussion, the focus of the present paper is on the development of a strategic policy scenario analysis framework, supporting an integrated planning approach of peripheral small island regions, with particular emphasis on alternative tourist development paths, which can be used as a 'vehicle' so as sustainability objectives to be reached. This framework is implemented to a peripheral small island region, the island of Lefkada-Greece. Lefkada, although rich in natural and cultural resources, has taken little advantage of their sustainable tourist development potential, while the gradually growing mass tourism model has already started to show certain negative signs regarding the particular resources. An integrated planning approach for sustainable resource exploitation can support decision-making towards seeking a qualitative, environmentally-responsible, spatially-balanced and strongly interacting with local economic sectors tourist development, thus creating new potential for economic prosperity, social cohesion, and respect to local natural and cultural assets. The proposed planning framework is supported by foresight and participatory evaluation tools, aiming at structuring and evaluating sustainable future tourist development scenarios, in order to conclude with the most challenging future options. The scenario building process takes into consideration developments of both the internal environment (environmental deterioration, increasing pressure on local resources by mass tourism, land use conflicts, unemployment, population decline etc.) and the external environment (strategic objectives of tourist development at a national level; global trends towards more environmentally-responsible alternative tourist paths; tourist policy directions at the EU level; etc.).

The structure of the paper has as follows: in the " 2 nd section", the proposed methodological framework for planning the sustainable future tourist development of peripheral small island regions is presented; in " 3 rd section" the main elements of the external environment, as factors that are framing the 'decision environment' within which the sustainable future tourist options for such regions can be sought, are shortly discussed; in "4th section", the key elements of the internal environment, i.e. attributes of the study region and the current state of the tourist sector in it, are explored; "5th section" elaborates on the structuring and evaluation of future tourist development scenarios that fulfill goals and objectives set for the study region; and finally, in "6th section" some conclusions are drawn, based on the experience gained from the application of the proposed framework. 


\section{The methodological approach}

The methodological approach consists of the following five steps (Fig. 1):

- Step 1: goal setting - sustainable tourist development of the study region - together with a number of objectives that fall into this particular goal.

- Step 2: exploration of the external environment in order to identify the context, within which policy decisions regarding the development of the tourist sector in the specific case study will be made. This is carried out at the international (market and non-market related factors), EU and national level.

- Step 3: study of the internal environment aiming at exploring the general attributes of the study region (environmental, economic and social), the current state of the tourist sector (e.g. potential, spatial development), etc.

- Step 4: structuring of scenarios for the sustainable tourist development of the study region. In these scenarios, emphasis is placed on the spatial pattern of tourist development, in an effort to seek a compromise between the development of the tourist sector and the need to protect the valuable ecosystems of the region; but also achieve, based on resource availability and distribution, a more spatially-balanced development of the sector, better integrated to the region's natural, cultural, economic and social environment, better interacting with the rest of local economic sectors, and finally better adjusted to challenges of the external decision environment.

- Step 5: participatory evaluation of future tourist development scenarios for the region at hand is carried out at this step by use of the NAIADE multicriteria evaluation model, supporting scenarios' prioritization from local stakeholders. Potential coalitions among the various stakeholders as to the proposed scenarios are also explored. The outcome of this step is the final decision, i.e. the most preferred tourist development scenario, guiding decisionmaking towards sustainable futures.

In the following, the application of the above policy analysis framework in the specific Greek peripheral small island region - the island of Lefkada - is presented.

\section{Key elements of the external environment}

Chon and Olsen [13:213] state that "... today's tourism environment is increasingly competitive and complex ... and tourism organizations at the national, state and local levels must make estimates about what is likely to happen in the future and decide how to adjust to future events". This statement implies a need to explore global challenges and threats of the external environment and structure future options for each single tourist destination that are adjustable to external signs noticed. In this respect, the present section aims at grasping key drivers of the external environment (see Fig. 1) which
Fig. 1 The methodological framework

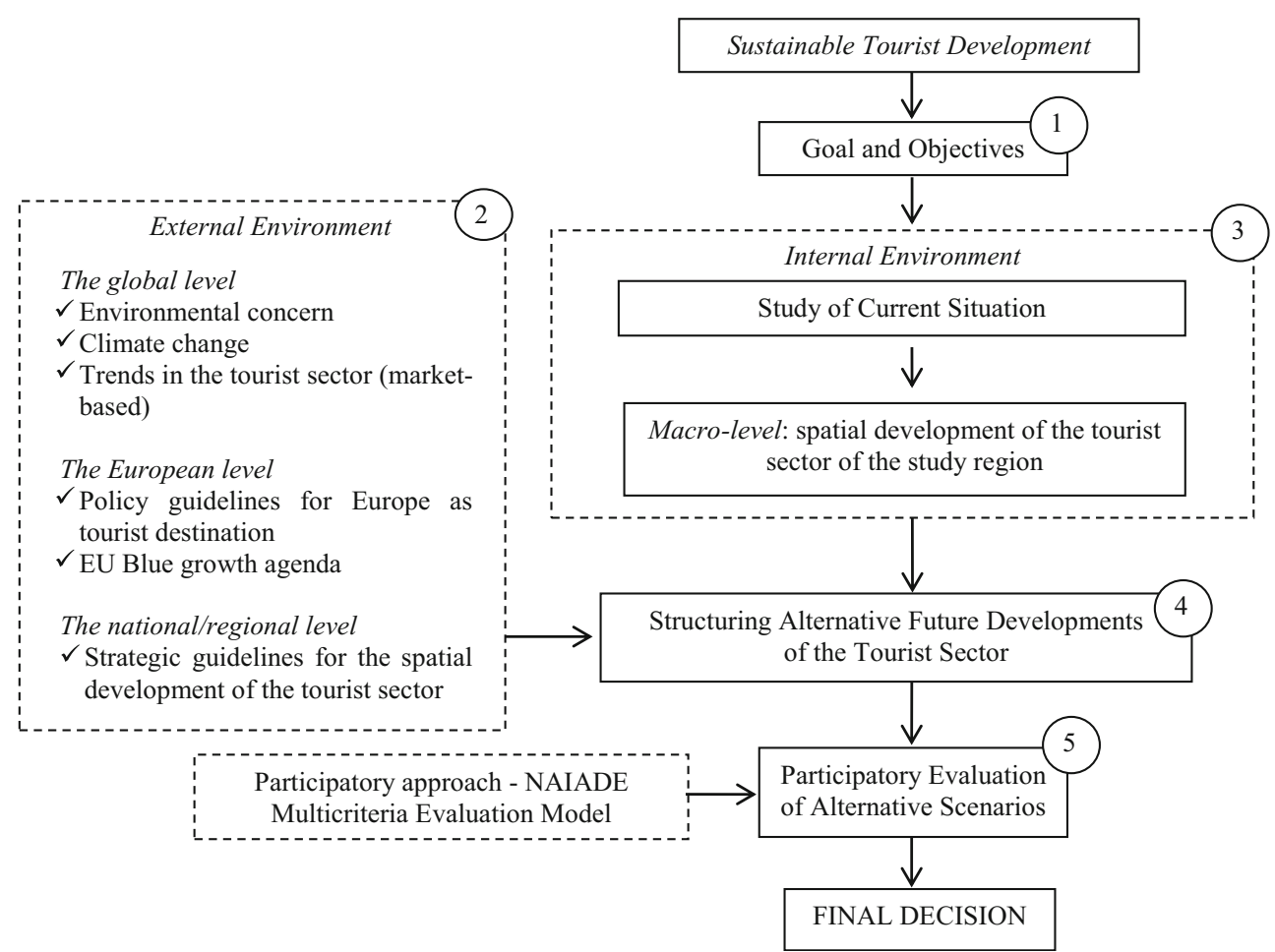


will, to a certain extent, frame decision-making on the future development of the tourist sector in the specific case study.

\section{The global context}

In searching of a sustainable future tourist development perspective of peripheral small island regions, certain key challenges emerge from the external environment (ranging from the global to the national/regional context), which need to be taken into consideration. In the present methodological approach, key drivers, trends and potential events are sought by exploring the issues, which are shortly described in the following (see Fig. 1):

- Environmental concern

The environmental impacts of tourist development are extremely important, since an unsustainable pattern that exceeds carrying capacity of a destination, particularly of a small island region, can largely degrade the natural and built environment. Key elements that should be taken into account in the planning exercise are:

- Depletion of natural resources, applying to: a) water resources, where key issues are water shortage (due to water overuse in hotels, swimming pools, golf courses, etc.), and production of a large volume of waste water; b) land degradation, as a result of the construction of tourist and recreational facilities; c) depletion of local resources, as tourist development exerts pressure on energy, food and other raw materials;

- Air pollution and noise, due to increased traffic patterns of the tourist destination;

- Solid waste and littering, constituting a severe problem and a potential risk for the natural environment if not properly handled, especially for small island regions;

- Sewage pollution, where water waste can be a source of pollution of sea and ground waters surrounding tourist attractions, resulting also in damages in destination's flora and fauna;

- Aesthetic pollution, due to the sprawl of tourist facilities along coastlines, valleys and scenic routes;

- Physical impacts, relating to the degradation of fragile ecosystems by tourism-related activities and infrastructures as well as the long-term structural changes taking place in the natural and built environment of a destination.

- Climate change

The role of climate in the development of the tourist sector is essential, as tourism is a highly climate-sensitive economic sector. Climate change can affect all types of tourist activities and destinations, i.e. summer or winter tourist activities and respective coastal, small islands or mountainous tourist regions, thus leading to a considerable restructuring of tourist destinations around the globe. The impacts of human actions on climate and weather patterns and their decisive importance for the development of the tourist sector are nowadays largely realized [14], as these may considerably affect tourists' comfort and thus travel decisions while, in extreme cases, they can even threaten travelers' safety, as past experience has shown (tsunami, floods, excessive heat, etc.).

Extreme weather episodes are increasing in frequency and intensity worldwide. Climate change impacts seem to be more pervasive in coastal and island tourist destinations, taking the form of storms and extreme climatic events, coastal erosion, physical damage to infrastructures, sea level rise, flooding, water shortage and water contamination [15], while high vulnerability of these regions often couples with a low adaptive capacity, especially in developing countries. The high vulnerability of island regions has also to be taken into consideration in the light of tourism's strong seasonality (mainly mass coastal tourism in peak summer periods), as in many island and coastal destinations the peak tourist season coincides with low water regimes in dry periods, aggravating water management and environmental issues [15]. As UNEP-WTO study states, “... the largest warming is likely to be in northern Europe in winter and the Mediterranean area in summer" [15:68].

Tourist sector is not only largely affected by climate change conditions, but it is also one - and non-negligible - contributor to the climate change challenge, due to the greenhouse gas emissions produced by tourist transport and accommodation activities. In this respect, various studies emphasize the need for policy action for: mitigating greenhouse emissions from the sector; adapting tourism businesses and destinations to changing climate conditions; and applying state-of-the-art and new technologies to improve energy and water efficiency performance. The strengthening of the tourist sector (business and leisure) as a producer of economic and social value at a global scale and its contribution to sustainable development agenda implies the urgent need for coherent policy strategies that can build a truly sustainable tourism model, reflecting "... a quadruple bottom line of environmental, social, economic and climate responsiveness" [15:28].

- Trends in the tourist sector

International tourism is anticipated to hit a new record by the end of 2014 with over 1.1 billion international tourists travelling worldwide in one single year. During the first 10 months of 2014, the number of international tourists grew by $5 \%$ according to the latest UNWTO World Tourism Barometer, rising above expectations. Between January and October 2014, the international tourists' volume (overnight visitors) reached 978 million, 45 million more compared with the same period of 2013. 
With an increase of $4.7 \%$, international tourism continues to grow well above the long-term trend projected by UNWTO for the period 2010-2020 (+3.8\%), and is set to end the year at over 1.1 billion [16]. Quoting Ban KiMoon, the UN Secretary-General, on World Tourism Day 2012, '... one of the world's largest economic sectors, tourism, is especially well-placed to promote environmental sustainability, green growth and our struggle against climate change through its relationship with energy'. Moreover, World Leaders meeting at two major summits, the United Nations Conference on Sustainable Development (Rio+20) and the G20 Summit in Mexico, agreed that tourism can make an important contribution to many of the world's most pressing challenges, from economic growth to climate change, and recognized tourism as an economic powerhouse and contributor to all three pillars of sustainable development (economic, environmental and social dimension). The above description is indicative of the role that tourist sector can play as a key driver of growth for the world economy, but also an important player for coping with current global challenges, taking into consideration the close interaction of the sector with the environmental and cultural resources of tourist destinations.

Key trends appearing nowadays in the sector are driven by both increasing environmental awareness and huge developments in the Information and Communication Technologies (ICTs) sector. The mainstream of these trends refer to the demand and supply but also the destination side and can be shortly described as follows:

On the demand side: a persisting trend appears towards more 'demanding' consumers, increasingly seeking a completely diversified tourist experience that is, based on their preferences, furthermore personalized. Moreover, accessibility benefits gained through ICTs increase travelers' knowledge on potential destinations, thus enhancing decision-making potential [17]. Based on that knowledge, tourists nowadays appear as 'mature consumers', i.e. more experienced, sophisticated, educated, knowledgeable and demanding, independent, flexible, more 'green-oriented' [18]. Finally, as the motivation to travel is gradually shifting from the need to 'escape daily routine' to a desire to 'experience and learn', consumers are increasingly seeking new, meaningful and authentic experiences [18, 19].

On the supply side: the exploitation of technology is nowadays critical for the tourism industry so as to achieve competitive advantage and provide economic benefits for localities, by reducing the asymmetric distribution of economic, political, and cultural capital globally. ICTs and their applications enable tourists and businesses to participate in the emerging electronic market and benefit from arising opportunities. Based on that, the supply side will manage to meet the growing trend towards the customization of the tourist product, by establishing the potential for a 'one-to-one' but also a 'win-win' marketing approach (customers and businesses). This newly evolving production environment values the most efficient relationships that are based on the creation of alliances, partnerships and networks among firms, enhanced by the emergence of ICTs. Tourist stakeholders with an ability to learn quickly, collaborate and translate that learning into active sharing of online experience, will be able to gain competitive advantages in these rapidly changing marketplaces [20, 21], and meet the demand for promoting a uniform and complete tourist experience [22]. Moreover, environmental protection objectives reengineer production processes of the tourist sector in order the demand for environmentally-committed tourist businesses and products to be effectively satisfied [23].

On the destination side: the changing characteristics of the tourist market call for the development of new products and services for meeting newly emerging special interest markets [24]. This can potentially influence, among others, the destinations' management. More specifically, these trends have implications on destination policy, planning and development; destination management organization; destination marketing management; risk management; and tourism education [24]. As today's tourists are well-travelled, sophisticated and demand quality and value, it is important for destination management to develop targeted and increasingly theme-based tourism products and services that are broadly oriented to one or a combination of three $e$-words: entertainment, excitement and education/experience of visitors [25]. Destinations' marketing has also been largely affected by developments of information technology and social media, increasing competition among destinations but also strengthening the potential of remote and peripheral regions to ambitiously enter the tourist market $[17,18]$. Coordination of marketing communication needs and networking among local decision makers and important tourist stakeholders could facilitate the ultimate goal of providing a holistic and coherent message towards tourist clients [26].

\section{The EU context - tourist policy guidelines}

Europe constitutes a very attractive tourist destination at a global scale, based on the quality and diversity of natural and cultural resources, a fact that renders tourist sector a considerable factor of growth and job creation in the European territory. In order to take advantage of these resources, a new political framework for tourist development of the European territory has been set that aims at strengthening the position of 
Europe as a global tourist destination [27]. Reaching this goal emphasizes, among others, the need for protecting natural and cultural heritage as well as traditions and contemporary cultures, setting the ground for tourist development across Europe. Moreover, this goal is confronted with a number of challenges, the most important of which are the [27]:

- increasing global competition, with newly emerging tourist destinations in numerous countries, implying the need for focusing on the provision of sustainable and highquality tourist products based on Europe's competitive advantages, with emphasis on the diversity of its countryside and extraordinary cultural wealth;

- changing demographic pattern observed in Europe, calling for specific adaptations of the tourist industry in order to take advantage of new tourist clients, e.g. aged target groups or target groups with reduced mobility and particular needs, which have to be integrated into the tourist supply and service structure;

- constraints linked to climate change, scarcity of resources, pressure on biodiversity, risks regarding the cultural heritage posed by mass tourism etc., which need to be considered by tourist businesses for formulating actions/ strategies that address the reduction of their environmental footprint;

- climate change impacts, which can alter the pattern of European tourist destinations, e.g. fall in winter tourism by declining snow patterns in mountainous regions or changes of coastal tourism by rising sea levels. The need for proactive planning approaches is stressed, for coping with potential structural unemployment and effective tourism-related investments necessary for the adjustment of tourist businesses to these impacts;

- challenges determined by the particular characteristics of the European tourist sector, linked to both consumer models, particularly seasonal distribution of tourist movements that affects revenue flows and results in nonoptimum use of existing infrastructures and staff; and production models, i.e. the value chain and tourist destinations.

To compete at the global scene, quality of local European tourist destinations needs to be assured, which implies that tourist development of destinations should be addressed by means of an integrated approach, keeping balance among all three sustainability pillars, i.e. protection of natural and cultural resources; socio-economic cohesion of destinations' communities; and economic development of regions involved, rather than placing emphasis only on the economic prosperity of the tourist sector. This implies the setting of appropriate public policies, targeting the sustainable management of destinations, the integration of sustainability concerns into tourist businesses and the promotion of tourists' sustainability awareness.
One also important European initiative is presented by the Communication [28] on the 'Blue Growth opportunities for marine and maritime sustainable growth', where the importance of sea and coasts as drivers of a new perspective of the economy - the blue economy, is stressed. Along this rationale, maritime, coastal and cruise tourism constitute one of the blue growth focus areas, where emphasis is given on coastal and open-water recreation activities. The potential of such activities for the European tourist sector is high, taking into consideration the specific challenges and opportunities posed by the five sea basins surrounding the European continent, namely the Atlantic ocean, North sea, Baltic sea, Black sea, and Mediterranean - Adriatic - Ionian seas.

\section{The national/regional context - tourist policy guidelines}

Future tourist development of the island of Lefkada has to take into consideration strategic directions for the tourist sector that are set at the national / regional policy level, which are shortly described in this section.

The tourist sector is one of the most important economic sectors, the 'heavy industry' of the Greek economy, whose development has, during the last decades, been mainly based on the mass tourist model, thus exhibiting a high concentration in both time (high seasonality) and space (high levels of spatial concentration at the coastline and islands). This tourist development pattern has in turn resulted in an increasing pressure, exerted on the natural, cultural and social resources of certain regions; and a limited exploitation of resources of other regions, contributing, among others, to the increase of regional inequalities $[29,30]$.

To cope with these inefficiencies, the Special Framework for Regional Planning and Sustainable Development of the Tourist Sector (SF-T) has been set up by the central government in 2009, consisting of the basic legislative document in the effort to define the strategic directions towards a diversified, more spatially-balanced and sustainable tourist development, assuring the smooth co-existence with the rest of economic sectors, but also the least disturbance of the natural and cultural resources [31]. The SF-T framework expresses the long term national policy for the spatial development of the tourist sector (2009-2024) and an action plan for the sustainable tourist development at the country level. The SF-T was revised in 2013 in order strategic choices both at the EU ('Lisbon strategy' in 2010, 'Europe as the top tourist destination' in 2010, etc.) and the national level (Protection of biodiversity, European Convention on Landscape, etc.) to be incorporated. Taking into consideration also the current unfavorable fiscal position of the country, the above revision aimed at establishing an upgraded legislative framework, capable of improving the attractiveness of Greek regions to tourist entrepreneurial investment decisions. Based on the SF-T, the Region of the Ionian Islands in general, and Lefkada island (study region) in 
particular, exhibit certain comparative advantages, emanating from the:

- central position in the Adriatic-Ionian Sea, which can significantly support the development of the tourist sector;

- upgraded ports network that can serve sea transportation purposes;

- valuable cultural and natural environment that can steer the development of highly qualitative alternative forms of tourism; and

- high potential to expand their area of influence by connecting to large sea transport routes.

According to the specific guidelines deriving from the SF$\mathrm{T}$, the island of Lefkada falls within a specific group of Greek islands - Group II, incorporating islands that are developed as tourist destinations, while the rest economic sectors are also developing on the grounds of available resources. Of key importance with regard to this type of islands is the conflict management among the various sectors, energy efficiency of tourist accommodation, development of other sectors of local economic structure, etc. Moreover, maritime tourism activities are predicted in the island of Lefkada.

Finally, the study of the external environment needs to keep in track with development priorities set for the Region of Ionian Islands for the time span 2007-2013, prolonged also in the period 2014-2020. These highlight the importance of the:

- qualitative development of the tourist sector, based on the distinguished cultural resources of the Ionian islands,

- innovative / qualitative and environmentally-friendly agricultural production,

- upgrading of tourist infrastructures and the certification of tourist services, and finally
- training of human resources for improving skills on tourist services.

\section{The internal environment}

The analysis of the current situation of the study system at hand is a necessary stage for planning its future development. In this respect, a short description of the general attributes of the study region - island of Lefkada - follows as well as the current state of the tourist sector.

The island of Lefkada belongs to the Heptanese cluster of Ionian Islands (Fig. 2a). It forms a complex of islands together with Kastos and Kalamos, constituting the municipality of Lefkada. The island is endowed with valuable natural resources (biodiversity, mountainous part, exceptional landscapes, caves etc.). Certain parts of the island (both land and sea parts) are placed among the protected areas of NATURA 2000 (Fig. 2b). Moreover, a wide variety of cultural resources are contributing to the formation of the specific "place identity' [32] of the Lefkada island, such as important archaeological and historical sites, local traditions and architecture, traditional music, traditional settlements, etc.

The Region of Ionian islands in general and Lefkada island in particular, are exhibiting low unemployment rates, mostly due to the development of the tourist sector, which absorbs a large number of employees, especially in the peak summer period. The local economic structure of Lefkada island is marked by the continuously declining trajectory of the primary sector; the more or less stabilized trajectory of the secondary sector, which steadily holds the third position in the local economic structure; while the tertiary sector rates first, mainly

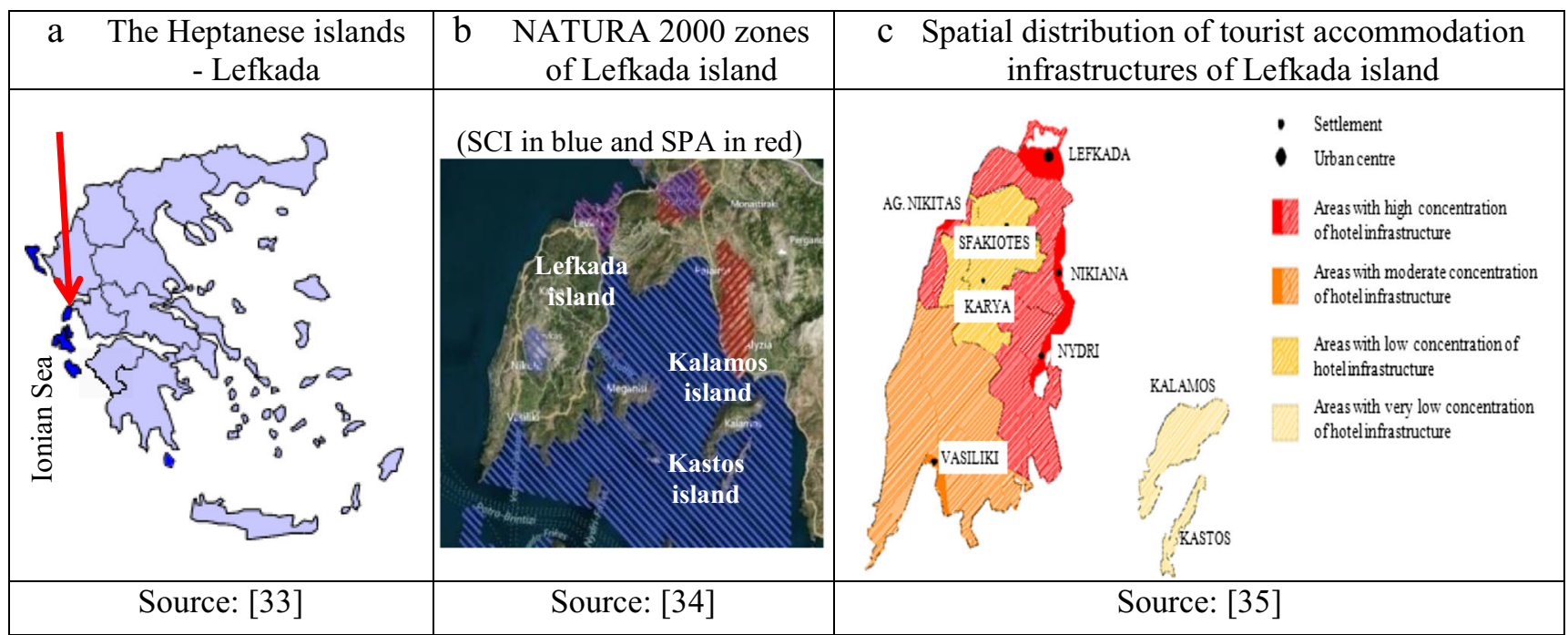

Fig. 2 The study region. a The Heptanese islands - Lefkada. Source: [33]. b NATURA 2000 zones of Lefkada island. Source: [34]. c Spatial distribution of tourist accommodation infrastructures of Lefkada island. Source: [35] 
due to the prevalence of the tourist sector but also the tertiarization trend of the local economy in general.

The tourist sector is mainly characterized by a mass pattern which, based on the rapid tourist development during the last few decades, has driven the weathering of the built and natural environment, the irrational use of local resources but also the intensification of land use conflicts in the island.

The tourist supply is mostly concentrated in the eastern coastal part of Lefkada, where the main body of hotel infrastructures and rooms to let are located (Fig. 2c). The emphasis placed on the tourist sector has resulted in a certain increase of hosting infrastructures (hotels and family-run rooms to let) during the last few years, resulting in a significant environmental degradation but also in conflicts against other sectors' interests. The low class level of the majority of these infrastructures reflects the low budget tourist flows attracted in the area.

As to the demand side, a steadily increasing number of tourist flows is noticed during the last years. The study of domestic and foreign flows shows the prevalence of domestic flows in the study area, while foreign flows exhibit a slight decrease [35].

\section{Structuring and evaluating scenarios for the sustainable future tourist development of Lefkada Island}

As Hudson et al. [36] state, an attractive, well functioning and competitive tourist destination is not created by chance, but is the outcome of successful planning, seeking to capitalize on local assets and promote forms of tourist development that are well adjusted to the local and global context. The scope of planning in this respect is the identification of strategic policy options that will effectively establish the 'link' between these two contexts, thus assuring efficient reaction of local regions to emerging external global challenges $[37,38]$. The latter is of crucial importance for long term success and is an issue that hasn't, up to date, drawn much attention from tourist destinations [39].

Planning the sustainable tourist development of a specific region is certainly a complex issue. The reason for that derives from the need to compromise economic, social and environmental objectives lying behind such an exercise [23, 40]. This implies a meaningful balance among different stakes so that the planning outcome responds to the needs and expectations of various stakeholders' groups [17], which in turn leads to commitment and ownership of planning goals and objectives and thus increases successful implementation of planning outcomes [41]. Moreover, it also needs to successfully compromise economic with social and environmental dimensions, in an effort to embody the social and environmental concern in the planning outcome, since tourism is an industry capitalizing on nature's endowments and society's heritage [39, 42, 43].

Such a multi-objective balance is sought in the following, by means of structuring and evaluating alternative scenarios for the sustainable tourist development of Lefkada island, taking into consideration opportunities and threats of the previously sketched external environment, as well as advantages and weaknesses emerging from the study of the internal environment (Lefkada island).

\section{Goal and objectives}

The first step of the scenario building process regards the delineation of the goal of the planning exercise. As such is defined the sustainable future development of the tourist sector in the small peripheral island of Lefkada, demarcated as an environmentally-responsible, socially-cohesive, economically-competitive and spatially-balanced sector, smoothly integrating into the local economic structure. This goal is further analyzed into a range of objectives which are keeping in track with the rationale introduced by the National Special Framework for Spatial Planning and Sustainable Development for Tourism [31], properly adjusted to the specific island region. These are:

- Restraining of population decline in various local settlements: it is worth noting the trend of abandoning small scale settlements of the hinterland for the benefit of the capital or other coastal settlements of the island, where the tourist sector prevails. This trend is hampering a balanced population distribution and a multi-sectoral development perspective of the study region $[31,35]$.

- Increasing interaction of tourist with other economic sectors: the region has a range of valuable local primary and manufactured products, which can serve the needs of the tourist sector, strengthening thus interaction among local economic sectors. Moreover, the development of the primary and secondary sector can set the ground for settling a range of alternative tourist activities e.g. agro-tourism activities [31,35].

- De-concentrated spatial pattern of tourist development: a shift from the current concentrated pattern of mainly mass tourist development to a de-concentrated spatial pattern is pursued, rating thus at a high position alternative tourist activities that contribute to the sustainable exploitation of local resources, the diversification of tourist product, and a more spatially balanced pattern of tourist development $[31,35]$.

- Upgrading of tourist accommodation infrastructures in quantitative, qualitative and energy-efficiency terms: based on the highly resource-intensive nature of accommodation infrastructures (heating and cooling, lighting, etc.), mostly concentrating in specific peak periods of 
time, the promotion of an environmentally-responsible pattern of tourist accommodation deployment is of outmost importance [31, 44].

- Upgrading of transport and telecommunications networks: considered as of crucial importance for providing unimpeded access of tourist flows to the study region, both in physical and electronic terms; while it can support local business networking and direct accessibility of local tourist businesses to tourist clients $[44,45]$.

- Upgrading of human resources: concerns stepping up of labour skills in respect of all kinds of economic activities, with particular emphasis on skills relating to the tourist sector $[31,35]$.

\section{Structuring of alternative scenarios}

The scenario approach is a foresight technique that is used for medium to long-term strategic analysis and planning, aiming at exploring possible alternative futures [46]. Scenarios, in this respect, intend to represent future states that are plausible, internally consistent, based on rigorous analysis, engaging and compelling. They set the ground, upon which robust, resilient, flexible and innovative strategic policies are sought [47], turned thus into useful 'management tools' for both private and public institutions [48].

In order scenarios to be structured, a range of alternative methodologies can be adopted, whose selection depends on the particular context of the study. It is important to keep in mind the need to explore a range of plausible futures, which can fulfill goals and objectives and present a portfolio of possible future states of the region at hand within different decision environments [49], thus complementing and informing decision-making and planning processes [50]. Moreover, such an exploration can also contribute to the identification of risks, and provide a more robust way of testing strategies [47], while it can also be a powerful tool for the anticipation of wild cards and adoption of proactive approaches for effectively coping with them [51].

From the set of available methodologies, the 'two uncertainty axes' scenario building process was applied to the specific foresight exercise [52]. The two uncertainty axes used in this respect refer to potential future developments of the tourist sector, used as a 'vehicle' for the integrated development of the island of Lefkada (see Fig. 3), and are: a) a horizontal axis delineating a diversifying emphasis on coastal and maritime alternative tourist activities (based on the 'blue growth' perspective of the tourist sector); and b) a vertical axis, expressing a diversifying emphasis on alternative tourism activities taking place in the hinterland (based on the 'green growth' perspective of the sector). These two policy directions ('green' and 'blue' growth) are considered by the research team as crucial for coping with challenges of the external environment (climate change impacts, environmental concern, tourist demand preferences, EU and national tourist policy directions etc.), while they can create a proper internal environment for reaching goal and objectives set for the region at hand. The two axes lead to the delineation of four qualitative, normative, contrasting, well differentiated future scenarios, which are further enriched by fleshing them out with lower level details to complete each specific future 'scenario' and properly communicate it to local stakeholders. Target year of this scenario exercise is considered 10 years, in order to be fully established infrastructural changes, change of behavioural pattern of local stakeholders, environmentally-friendly spirit in the local community, development of alternative tourist activities and related hosting infrastructure etc. It should be noted the emphasis placed on the promotion of an alternative tourist model, which aims at coping with sustainability threats imposed by the prevailing mass tourism direction the island follows at present; and the structuring of a more spatially balanced tourist development. Both are presented by all three scenarios apart from scenario A (worst-case or BAU scenario).

Below, the four scenario narratives are shortly presented. More specifically (see Fig. 3):

\section{- Scenario A - Worst case scenario (BAU)}

This scenario is emerging from the extrapolation of past and current trends, actually representing a low level of exploitation of green and blue growth perspectives of the tourist sector. The tourist sector, mainly based on the mass tourist model, is prevailing in the local economy. This model, although it has currently brought certain economic benefits, it has also already revealed the first signs of fatigue with regard to the local natural and cultural as well as social resources, which may threaten the future of the region and the tourist sector per se in the long term. The share of primary and secondary sector of the local economic structure is steadily declining, threatening the stability (mono-sectoral development) but also competitiveness of the local economy. Based on the dominant low environmentally-friendly culture, environmental and cultural resources are gradually deteriorating, leading thus to the jeopardization of the comparative advantage upon which the tourist product is based. Quality of tourist flows is downgraded, threatening the sector's long term flourishing. The island's high dependence on the tourist sector increases vulnerability of the local economy to external threats (e.g. climate change, volatile tourist demand, economic recession), while the mass tourist model weakens the potential for grasping new market opportunities, emerging from the global tourist market place (e.g. qualitative environmentally-committed tourist demand).

- Scenario B - Shift to the hinterland - 'Green' tourist development 
Fig. 3 Future tourist development scenarios based on the two uncertainty axes Lefkada island

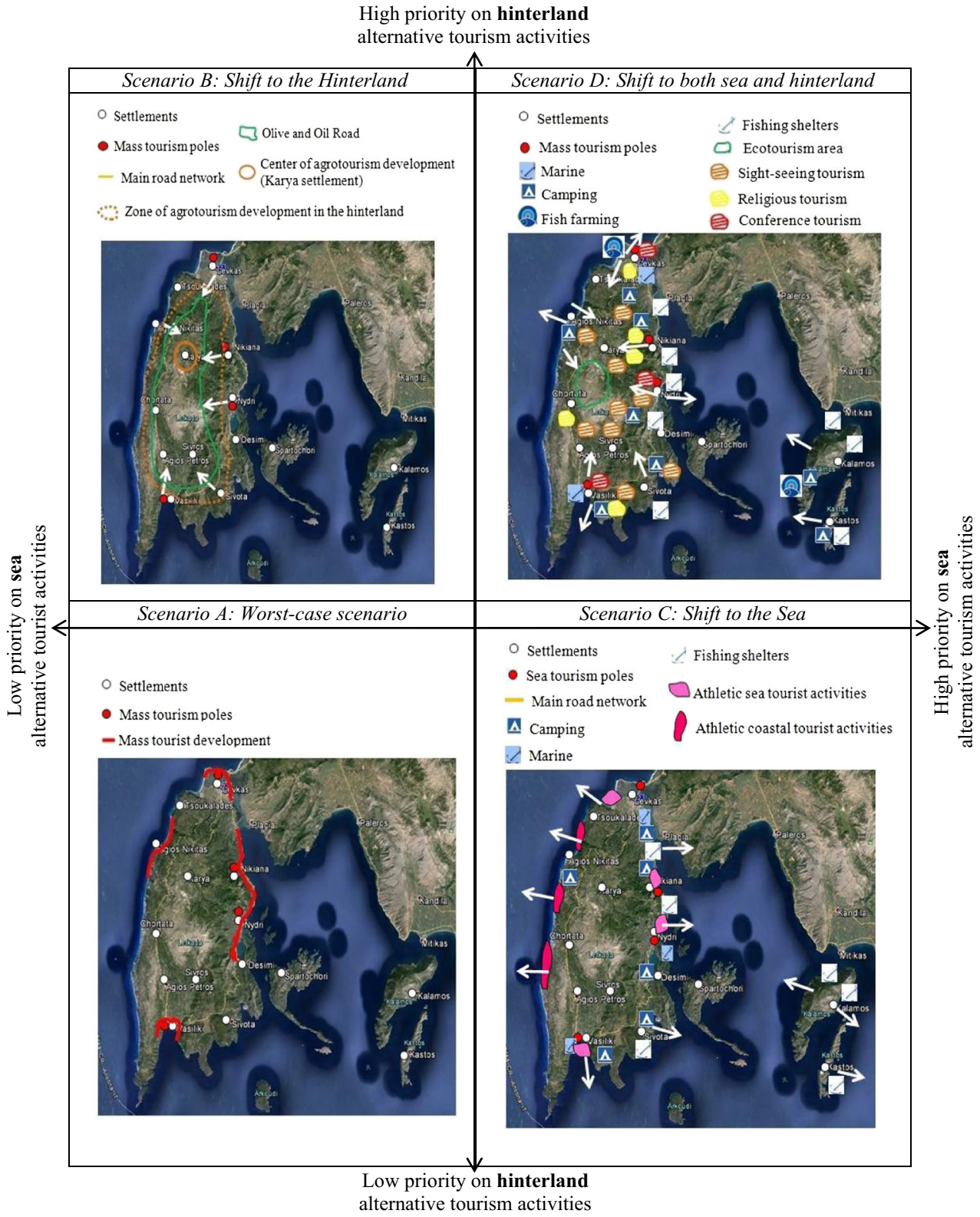

This scenario aims at the sustainable exploitation of a variety of natural and cultural resources, met in abundance in the island's hinterland ('green' growth perspective), which still remains unexploited. Environmentallyfriendly tourist activities are of high priority according to this scenario. The mass tourism model of the coastal part remains stable, with a shift towards more qualitative tourist flows and upgrading ('greening') of tourist infrastructures and services. The identity of the island is mainly based on the development of 'green' tourist activities. In this respect, a settlements' network is created in the hinterland, based on Karya settlement which is considered as the main pole of alternative tourist development. Local traditions, culture, gastronomy, agriculture, small scale manufacturing, traditional settlements, natural resources of the mountainous part, local products, such as wine and oil, etc. constitute the core of alternative tourist development, strongly connected with the mass coastal tourist poles for reaping the benefits of tourist flows and diffusing local identity values and local products. The green spirit is also permeating the primary and secondary sector, where green practices and technologies in conjunction with traditional way of producing leads to qualitative, certified agri-food products, highly appreciated by visitors. Finally, a range of interventions improve unimpeded movement between seaside and the hinterland, thus further diffusing values and local quality and enhancing opportunities for spreading services and products of the hinterland to the coastal part. 
- Scenario C - Shift to the sea - 'Blue' tourist development

According to the particular scenario, the identity of Lefkada as a tourist destination is broadly determined by athletic/sport sea activities developed in the coastal part, highlighting thus the 'blue growth' perspective of the island. Mass tourism model is restrained, while emphasis is placed on the development of a range of athletic/sport coastal poles, taking advantage of seaside areas, marine network developed in the island, sea caves and coastal configuration, weather conditions (winds) etc. Environmental culture prevails, leading to the development of a range of environmentally-friendly tourist activities. As such can be referred coastal athletic activities, diving, sea canoe-kayak, kite surf, wind surf, water skiing, yachting/sailing activities etc. Moreover, accommodation infrastructures of low nuisance are deployed in Kastos and Kalamos, the two small islands administratively belonging to Lefkada island. This has further expanded sea activities in Lefkada island complex (see Fig. 2b). The already existing sea sport activities are strengthened, rendering Lefkada an environmentally-committed athletic/sport centre for professional and amateur sport groups and a pole for the organization of national and international coastal and sea athletic events and activities; while mass tourist activities are still retained, located mostly at the eastern part of the island, which has also taken steps towards a more environmentally-friendly tourist business management.

- Scenario D - Shift to both sea and hinterland - Combined 'green' and 'blue' direction

The specific scenario aims at the upgrading of tourist services and the further enrichment of the tourist product of Lefkada island. More particularly, it focuses on the development of both coastal / maritime alternative tourist activities and alternative tourist activities in the hinterland. A high environmentally-friendly culture is prevailing in this scenario, permeating all sectors of the local economy, including the tourist sector. 'Green' and 'blue' developments of the tourist sector are highly integrated with the rest of the local economic sectors, which are also adjusted to the environmentallyfriendly spirit, with emphasis on the low ecological footprint of local traditional primary and secondary production. Sustainable exploitation of local natural and cultural resources have led to a rich tourist product, combining coastal and maritime tourist activities with cultural and religious tourism, agro-tourism, gastronomy tourism, wine tourism, etc. In such a context, a more spatially-balanced tourist development perspective of the island is achieved, motivating local stakeholders and population, keeping alive local traditions and culture, strengthening isolated regions of the island and providing the highest integration among local economic sectors; and a promising future for employment and income support as well diversification of the local economy, better responding to external risks that can threaten all sectors of the local economy.

\section{Participatory evaluation of alternative scenarios}

It is commonly accepted that in order sustainable tourism development in a specific destination to be achieved, an inclusive, strategic and long term oriented planning approach is necessary [41, 53], seeking consensus among local stakeholders on the selection of the most desired future direction.

In this section, the evaluation of the four previously described scenarios (Fig. 3) is taking place, based on: a) a participatory approach involving local stakeholders; and b) the use of the NAIADE multicriteria evaluation model [54], which deals with qualitative data, reflecting the views of local stakeholders as to the scenarios entering the evaluation stage (see also [41]).

\section{The NAIADE multicriteria evaluation method}

NAIADE (Novel Approach to Imprecise Assessment and Decision Environments) is a discrete multicriteria evaluation tool, suitable for planning problems characterized by high uncertainty and complexity as to existing spatial, social and economic structures and respective interrelationships among them [55]. The model deals with both quantitative and qualitative data. The basic input to NAIADE model is: a) the set of alternative scenarios to be evaluated; $b$ ) a number of decision criteria for their evaluation; and c) a number of stakeholders, who express judgments with respect to the scenarios at hand. Based on this input, are carried out [56]:

- a multicriteria analysis, which results in the prioritization of alternative scenarios as to a set of evaluation criteria; and

- an equity analysis, which explores the level of agreement among the different interests (stakeholders) as to the prioritization of alternative scenarios emerging from the previous step, and possible 'alliances' or 'conflicts' among stakeholders as to these particular scenarios.

a) Multicriteria analysis

The NAIADE multicriteria analysis aims at ranking alternative scenarios on the basis of their performance as to certain evaluation criteria. Towards this end, the impact matrix is used (criteria/alternatives matrix), incorporating scores that can take the following forms: crisp numbers, stochastic elements, fuzzy elements and linguistic elements (such as 'good', 'moderate' etc.) $[54,56]$. The comparison of alternative scenarios is based on the concept of 'distance' between two alternative scenarios as to a certain evaluation criterion. When dealing with crisp numbers, 
this distance is calculated by subtracting respective crisp numbers. In any other case, the concept of 'semantic distance' is used, measuring the distance between two functions, via which the scores of the alternative scenarios are expressed. The final ranking of alternatives is the outcome (intersection) of two separate rankings: the $\Phi^{+}$(a) ranking that is based on the 'better' and 'much better' preference relationships; and the $\Phi^{-}$(a) ranking that is based on the 'worse and 'much worse' preference relationships (for more information see [56]).

b) Equity analysis

The equity analysis constitutes the second step of the NAIADE method. The aim of the analysis is to explore potential 'alliances' or 'conflicts' among groups of stakeholders against alternative scenarios' prioritization. For this purpose, an equity matrix is constructed, whose elements represent, in a qualitative way (linguistic expressions), the judgments of stakeholders' groups in respect of alternative scenarios (i.e. different prioritization for each specific group according to own interests). Elaboration of these data results in the calculation of a similarity matrix, where the degree of judgments' similarity of each pair of stakeholders' groups $(\mathrm{i}, \mathrm{j})$ is presented. Calculations involved in this respect are based on the 'semantic distance' among the judgments of each single pair of stakeholders' groups for each alternative scenario [56]. The interpretation of the results emanating from this step can provide planners valuable information with respect to 'resistance' or 'consensus' reached among stakeholders' groups as to the proposed alternative scenarios.

\section{Application of the NAIADE model}

The application of the NAIADE model is based on the following qualitative data input: a) the previously presented four discrete scenarios; b) a set of ten evaluation criteria, emanating from goal and objectives set (Table 1); c) the impact matrix, presenting the performance of each scenario as to the evaluation criteria concerned (Table 2); d) the equity matrix, presenting the views of local stakeholders as to the scenarios concerned (Table 3).

\section{a) Data input}

Data presented in Table 3 was gathered in a participatory workshop organized in the island of Lefkada, involving local representatives from the three economic sectors (agriculture, manufacturing and tourist sectors), local administration representatives, representatives from local cultural and environmental associations and local population. The scope of the exercise was to involve all stakes that can have a certain potential to influence goal and objectives set. Towards this end, ten persons were involved, selected on the basis of their role as representatives of the different stakes. The focus group methodology was used in this participatory exercise, comprising the following steps: a) presentation of the scenario building rationale and respective scenarios, created by the research team; b) structured discussion on these scenarios in order to gather responses and views of interested stakes; and c) elaboration of responses by the research team in order to identify potential 'alliances' or 'conflicts' among stakeholders' judgments on scenarios' structuring and prioritization.

b) Empirical results

Table 1 Evaluation criteria

\begin{tabular}{|c|c|c|}
\hline $\mathrm{a} / \mathrm{a}$ & Domain & Evaluation criteria \\
\hline $\mathrm{K} 1$ & Environment & $\begin{array}{l}\text { Level of sustainable exploitation of natural } \\
\text { and cultural resources }\end{array}$ \\
\hline $\mathrm{K} 2$ & & Level of vulnerable ecosystems' protection \\
\hline $\mathrm{K} 3$ & Economy & Level of new employment expected \\
\hline K4 & & $\begin{array}{l}\text { Promotion of local products - level of interaction } \\
\text { of the tourist sector with the rest of the } \\
\text { local economic sectors }\end{array}$ \\
\hline K5 & & Level of alternative tourism development \\
\hline K6 & Society & Level of social and economic cohesion created \\
\hline K7 & & Level of population restraint \\
\hline K8 & & $\begin{array}{l}\text { Level of awareness raising in the local society } \\
\text { (business and societal level) }\end{array}$ \\
\hline K9 & Spatial pattern & $\begin{array}{l}\text { Level of spatially balanced development of the } \\
\text { tourist sector }\end{array}$ \\
\hline K10 & $\begin{array}{l}\text { Tourist accommodation } \\
\text { infrastructures }\end{array}$ & $\begin{array}{l}\text { Level of environmental culture permeating tourist } \\
\text { businesses - Ecological footprint of tourist businesses }\end{array}$ \\
\hline
\end{tabular}


Table 2 Impact matrix

\begin{tabular}{|c|c|c|c|c|c|c|}
\hline & & Scenario & $\begin{array}{l}\text { Scenario A } \\
\text { Worst-case scenario }\end{array}$ & $\begin{array}{l}\text { Scenario B } \\
\text { Shift to hinterland }\end{array}$ & $\begin{array}{l}\text { Scenario C } \\
\text { Shift to sea }\end{array}$ & $\begin{array}{l}\text { Scenario D } \\
\text { Shift to both sea } \\
\text { and hinterland }\end{array}$ \\
\hline & Evaluation criteria & & & & & \\
\hline \multirow[t]{10}{*}{ Domain } & \multirow[t]{3}{*}{ Environment } & $\mathrm{K} 1$ & Very bad & Good & Moderate & Perfect \\
\hline & & $\mathrm{K} 2$ & More or Less Bad & More or Less Good & Very Good & Moderate \\
\hline & & $\mathrm{K} 3$ & Very Bad & Good & Moderate & Perfect \\
\hline & \multirow[t]{3}{*}{ Economy } & K4 & Very Bad & Perfect & More or Less Bad & Perfect \\
\hline & & K5 & Very bad & Good & Moderate & Perfect \\
\hline & & K6 & $\mathrm{Bad}$ & Very Good & More or Less Bad & Perfect \\
\hline & \multirow[t]{2}{*}{ Society } & $\mathrm{K} 7$ & $\mathrm{Bad}$ & Perfect & More or Less Bad & Very good \\
\hline & & K8 & Extremely Bad & Perfect & Moderate & Very Good \\
\hline & Spatial pattern & K9 & Very bad & Very good & More or Less Bad & Perfect \\
\hline & Hosting infrastructures & K10 & $\mathrm{Bad}$ & Very good & Moderate & Perfect \\
\hline
\end{tabular}

In this section, the empirical results of the specific evaluation problem are presented. These are divided into results obtained from the multicriteria analysis (prioritization of scenarios) and those obtained from equity analysis (alliances or conflicts among stakeholder groups involved as well as agreement or opposition to the scenario prioritization of the previous step).

\section{- Multicriteria analysis}

The empirical results obtained from the multicriteria module (Fig. 4) indicate that the most prevailing scenarios are Scenario B ('Shift to the hinterland') and Scenario D ('Shift to both sea and hinterland'), which are almost equivalent as to their performance. Next in rating comes Scenario C ('Shift to the sea'), while last rates Scenario A ('Worst-case scenario'), which performs rather worse in both $\Phi^{+}$and $\Phi^{-}$preference relationships.

\section{- Equity analysis}

In this section, the results emanating from the equity analysis are presented. More specifically, in Table 4 the degree of judgments' similarity of each pair of stakeholders' groups $(i, j)$ is shown; while in Fig. 5 the process of alliances' formation at different levels of agreement is depicted.

The results obtained from the equity analysis are used to explore potential 'alliances' or 'conflicts' among stakeholders' judgments on scenarios' prioritization. According to these results, it is quite evident that the highest level of coalition appears between cultural associations and local administration (0.9014), next follows the coalition of manufacturing and agricultural representatives $(0.8936)$, while tourism representatives seem to rather early differentiate their position as to the scenarios concerned (agreement with the rest of stakeholders at the lowest rate of agreement - 0.5998) (see Table 4 and Fig. 5).

In Table 5 coalitions created at the highest level of agreement (0.9014) together with the rating of scenarios of each specific group at this level are presented. From the above results is clearly evident the preference of Scenario B ('Shift to the hinterland') by all stakeholders with the exception of stakeholder $\mathrm{G}_{3}$ (tourism representatives). This is in alignment with the outcome of the multicriteria analysis prioritization. $\mathrm{G}_{3}$ rates first Scenario D ('Shift to both sea and hinterland'),

Table 3 Equity matrix

\begin{tabular}{|c|c|c|c|c|}
\hline Scenario & $\begin{array}{l}\text { Scenario A } \\
\text { 'Worst-case scenario' }\end{array}$ & $\begin{array}{l}\text { Scenario B } \\
\text { 'Shift to the hinterland' }\end{array}$ & $\begin{array}{l}\text { Scenario C } \\
\text { 'Shift to the sea' }\end{array}$ & $\begin{array}{l}\text { Scenario D } \\
\text { 'Shift to both sea } \\
\text { and hinterland' }\end{array}$ \\
\hline
\end{tabular}

Stakeholders' groups (G)

\begin{tabular}{|c|c|c|c|c|c|}
\hline Agricultural representatives & G1 & $\mathrm{Bad}$ & Perfect & Moderate & Very good \\
\hline Manufacturing representatives & G2 & $\mathrm{Bad}$ & Perfect & Moderate & Very good \\
\hline Tourism representatives & G3 & Moderate & Moderate & Very good & Perfect \\
\hline Local administration & G4 & Very bad & Very good & Good & Perfect \\
\hline Cultural association & G5 & Very bad & Perfect & Good & Very good \\
\hline Environmental association & G6 & Very bad & Perfect & Very good & Good \\
\hline Local population representatives & G7 & Very bad & Perfect & Moderate & Very good \\
\hline
\end{tabular}


Fig. 4 Results of multicriteria analysis

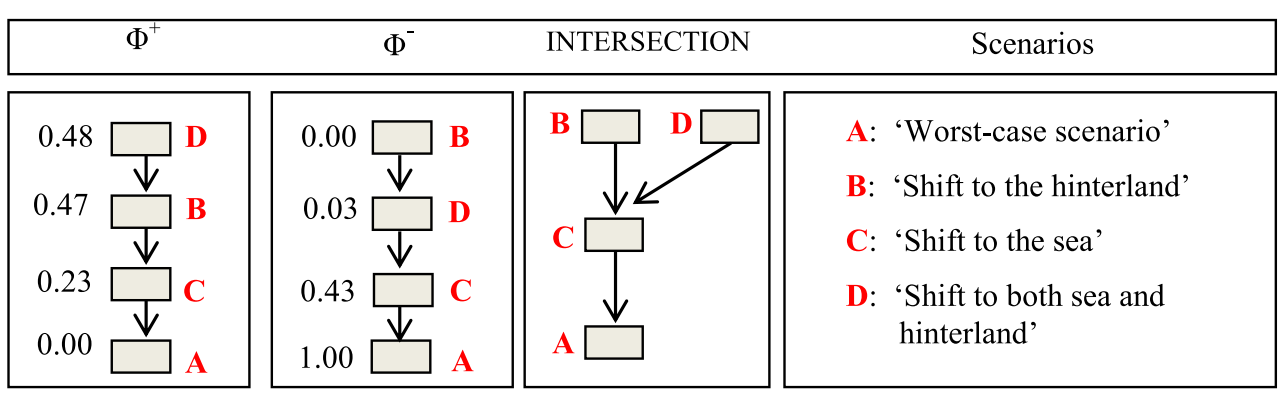

presenting more business opportunities for the tourist sector. The larger coalition for Scenario B (all stakeholders but tourism representatives) is explained by the range of opportunities presented by this scenario for the island as a whole, by sustainably exploiting local resources and spreading benefits in all economic sectors, achieving thus a better integration of these local economic sectors. Moreover, a certain agreement has been reached as to the second in sequence scenario, being Scenario D ('Shift to both sea and hinterland'), with the exception of $\mathrm{G}_{3}$ (tourism representatives) who have rated it first and $\mathrm{G}_{6}$ (Environmental association) who rates second Scenario C ('Shift to the Sea'). Stakeholder $\mathrm{G}_{6}$ seems to prefer scenarios $\mathrm{B}$ and $\mathrm{C}$, exhibiting the least nuisance as to the local assets. Finally, worst case scenario (Scenario A) is rated at the lowest level by all stakeholders' groups, which implies that a certain consensus is reached among the majority of these groups regarding the need for 'breaking' current mass tourism trajectory.

Certain low level of agreement (conflicts) among stakeholders' groups can also be noticed in Table 4, e.g. between tourism on the one hand and local population representatives $(0,5496)$ as well as environmental association $(0,5853)$ on the other, expressing opposing interests as to the sustainable exploitation of natural and cultural resources.

As Scenarios B ('Shift to the hinterland') and D (Shift to sea and hinterland') are almost equally performing as to the goal and objectives set in this planning exercise (see Fig. 4 above), it seems that decision makers and planners have certain flexibility in meeting local stakeholders' preferences by choosing between these two scenarios, properly adjusting the one selected in order to fulfill all stakeholders' expectations.

It should be also noted that an in depth analysis of results obtained from the NAIADE model can provide useful inferences for planners and decision makers in the study area, as to potential strong stakeholders' alliances that oppose to planning solutions or strong conflicts among stakeholders, both of which need to be properly handled for improving implementation potential of the final planning decision.

\section{Conclusions}

The focus of the present paper is on the sustainable tourist development of peripheral small island regions, setting as an example an island from the Greek territory disposing such attributes, the island of Lefkada. Development perspectives of such regions are fraught with difficulties. These are mainly due to their isolation from the hinterland, as witnessed in most European island regions [10], but also their limited capacity to cope with climate change impacts; volatile tourist demand due to decisions made by global tourist distribution channels; globalization effects and commands as to greater levels of efficiency, effectiveness, productivity and profitability of local businesses; etc. On the other hand, such regions are privileged in terms of natural and cultural heritage, a comparative

Table 4 Similarity matrix

\begin{tabular}{lllllllll}
\hline & $\mathrm{G}_{\mathrm{i}}$ & $\mathrm{G}_{1}$ & $\mathrm{G}_{2}$ & $\mathrm{G}_{3}$ & $\mathrm{G}_{4}$ & $\mathrm{G}_{5}$ & $\mathrm{G}_{6}$ & $\mathrm{G}_{7}$ \\
$\mathrm{G}_{\mathrm{i}}$ & & & & & & & & \\
\hline Agricultural representatives & $\mathrm{G}_{1}$ & 1.0000 & 0.8936 & 0.5722 & 0.7372 & 0.7396 & 0.6624 & 0.8460 \\
Manufacturing representatives & $\mathrm{G}_{2}$ & 0.8936 & 1.0000 & 0.5722 & 0.7372 & 0.7396 & 0.6624 & 0.8460 \\
Tourism representatives & $\mathrm{G}_{3}$ & 0.5722 & 0.5722 & 1.0000 & 0.5998 & 0.5888 & 0.5853 & 0.5496 \\
Local administration & $\mathrm{G}^{4}$ & 0.7372 & 0.7372 & 0.5998 & 1.0000 & 0.9014 & 0.7926 & 0.7706 \\
Cultural association & $\mathrm{G}_{5}$ & 0.7396 & 0.7396 & 0.5888 & 0.9014 & 1.0000 & 0.8155 & 0.7739 \\
Environmental association & $\mathrm{G}_{6}$ & 0.6624 & 0.6624 & 0.5853 & 0.7926 & 0.8155 & 1.0000 & 0.6734 \\
Local population & $\mathrm{G}_{7}$ & 0.8460 & 0.8460 & 0.5496 & 0.7706 & 0.7739 & 0.6734 & 1.0000 \\
representatives & & & & & & & & \\
\hline
\end{tabular}


Fig. 5 Dendrogram representing the process of alliances' formation

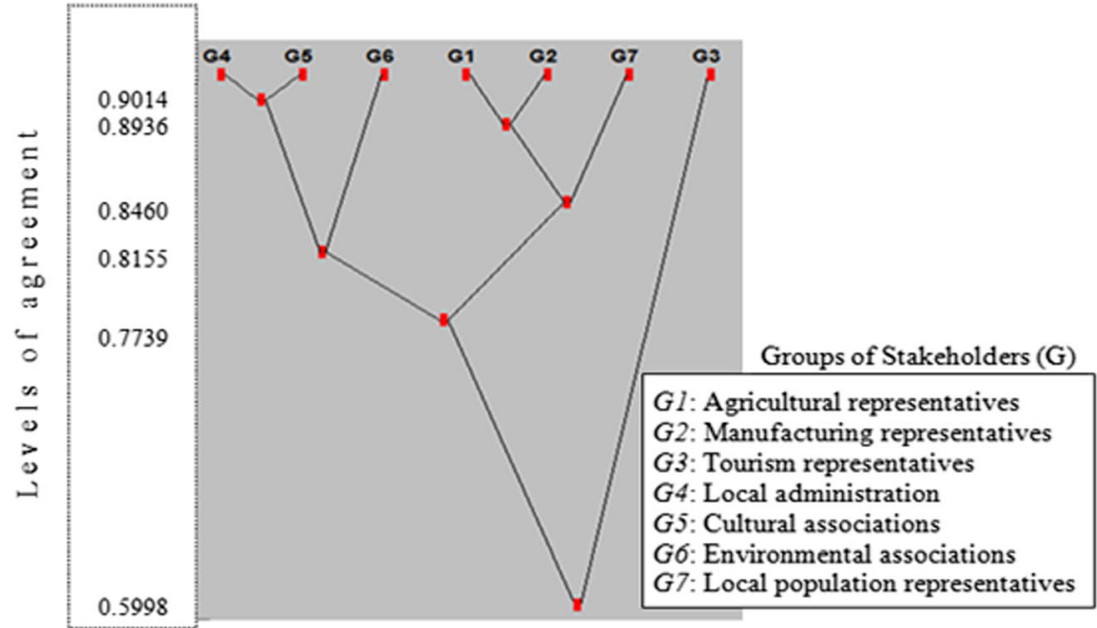

advantage which can, when sustainably exploited, support their long term competitive position in the global tourist scene, by capitalizing on these assets to differentiate on the basis of quality, multiple and unique experiences offered to visitors, peaceful scenic tourist routes and environmentally-committed products etc.

Sticking to competitiveness without sustainability of tourist destinations is illusory, while as stated by Ritchie and Crouch [57], a truly competitive destination is the one that perceives competitiveness from an economical, ecological, social, cultural and political point of view, bringing to the fore a quadruple bottom line approach integrating, in an equally balanced way, economic, environmental, social and political aspects [39]. Taking the above into account, it is clearly understood that strengthening competitiveness of peripheral small island regions highlights the need for destination planners and local decision makers to adopt more strategic, proactive, normative approaches which, based on strategic consensual visioning involving all interested parties, will be capable of creating more well structured views and thus more knowledgeable decisions for: keeping track with increasing market competitiveness; taking into consideration challenges and threats arising from the external environment; linking more effectively tourist destinations policy options with global developments and challenges; reaching consensus at the local level, where decisions made are consistent with values and expectations of local communities; and ensuring the achievement of sustainability objectives, for a more long term flourishing of such destinations $[39,57,58]$.

In order the above objectives to be fulfilled, a policy analysis framework is proposed, which sets the ground for guiding strategic policy decisions towards the sustainable tourist development of a peripheral small island region, LefkadaGreece. Four discrete sustainable future development scenarios of the tourist sector of the study area are presented which, apart from the worst-case scenario, are built upon a proactive and integrated approach of the sector, incorporating contemporary policy directions as to the 'green' and 'blue growth' alternative tourism perspectives. These are also drawn upon contemporary trends of the global tourist market, expressed by the shift towards more mature tourist flows, seeking new experiences of places, cultures, gastronomy, etc. The evaluation of these scenarios is based on a participatory multicriteria evaluation model, capable of dealing with both quantitative and qualitative data and of detecting potential alliances or conflicts among stakeholders' groups involved. The engagement of public and stakeholders in such a planning exercise can: establish a 'learning platform', facilitating information exchange and mutual understanding among participants, thus considered as the driving force towards a shared 'ground' of future developments of the specific region; support the gathering of valuable information on stakeholders' judgments on the proposed future development scenarios for further enriching the planning process and outcome; and ensure
Table 5 Coalitions at the highest level of agreement (0.9014)

\begin{tabular}{lllllll}
\hline$\left\{\mathrm{G}_{5}, \mathrm{G}_{4}\right\}$ & $\left\{\mathrm{G}_{3}\right\}$ & $\left\{\mathrm{G}_{6}\right\}$ & $\left\{\mathrm{G}_{7}\right\}$ & $\left\{\mathrm{G}_{2}\right\}$ & $\left\{\mathrm{G}_{1}\right\}$ & Alternative scenario \\
\hline $\mathrm{B}_{0.05}$ & $\mathrm{D}_{0.00}$ & $\mathrm{~B}_{0.00}$ & $\mathrm{~B}_{0.01}$ & $\mathrm{~B}_{0.00}$ & $\mathrm{~B}_{0.02}$ & $\mathrm{~A}$ - 'Worst case scenario' \\
$\mathrm{D}_{0.05}$ & $\mathrm{C}_{0.05}$ & $\mathrm{C}_{0.05}$ & $\mathrm{D}_{0.06}$ & $\mathrm{D}_{0.05}$ & $\mathrm{D}_{0.07}$ & $\mathrm{~B}$ - 'Shift to the hinterland - Green perspective' \\
$\mathrm{C}_{0.28}$ & $\mathrm{~B}_{0.50}$ & $\mathrm{D}_{0.20}$ & $\mathrm{C}_{0.45}$ & $\mathrm{C}_{0.50}$ & $\mathrm{C}_{0.48}$ & $\mathrm{C}$ - 'Shift to the sea - Blue perspective' \\
$\mathrm{A}_{1.35}$ & $\mathrm{~A}_{0.50}$ & $\mathrm{~A}_{0.95}$ & $\mathrm{~A}_{0.78}$ & $\mathrm{~A}_{0.80}$ & $\mathrm{~A}_{0.80}$ & $\begin{array}{c}\text { D - 'Shift to sea and hinterland - Green and blue } \\
\text { perspective' }\end{array}$ \\
\hline
\end{tabular}


credibility and transparency in the decision-making process. Moreover, for a successful planning outcome, it is important for planners to be able to identify the level of 'acceptability' of goals/objectives and resulting plans, which can drive their efforts for better orienting policy actions and reaching consensus on behalf of a more effective implementation of plans [41]. The latter is of crucial importance, as it can guide decision-making and support policy makers in coping with conflicting interests in the region at hand.

As to the area of concern, the analysis carried out shows that there is a strong need to 'break' existing tourist development pattern and build a more spatially balanced and environmentally responsible profile of the tourist sector in order local resources and identity for a lasting tourist development that copes successfully with sustainability objectives to be preserved. Participatory evaluation of the proposed future options proved a good exercise for establishing interaction among different interests, increasing mutual understanding among them and increasing awareness on the necessity for an integrated and of long term perspective towards the sustainable use of local assets and tourist development of the island. Based on that, the type and pace of tourist development, the necessary interventions towards this end, the social and cultural implications of preferred options, etc. can be explored.

The high level of consensus reached as to a certain scenario (Scenario B - 'Shift to the hinterland') reflects the need for realizing a tourist development perspective that builds upon all sectors ('green' tourist perspective), keeps in track and reinforces local identity, traditions, etc. and spreads the benefits reaped to the whole society. Moreover, the participatory evaluation exercise and the interaction with local stakeholders revealed to planners and local decision makers the "way to go', thus setting the ground for more sound policy decisions that reflect local preferences and will be able to fulfill present but also future development perspectives of this small peripheral Greek island.

Open Access This article is distributed under the terms of the Creative Commons Attribution 4.0 International License (http:// creativecommons.org/licenses/by/4.0/), which permits unrestricted use, distribution, and reproduction in any medium, provided you give appropriate credit to the original author(s) and the source, provide a link to the Creative Commons license, and indicate if changes were made.

\section{References}

1. WTTC (1995) Agenda 21 for the travel and tourism industry: towards environmentally sustainable development. World Travel and Tourism Council Report, London

2. Mihalic T (2000) Environmental management of a tourist destination: a factor of tourism competitiveness. Tour Manag 21:65-78
3. Go MF, Govers R (2000) Integrated quality management for tourist destinations: a European perspective on achieving competitiveness. Tour Manag 21:79-88

4. Hassan SS (2000) Determinants of market competitiveness in an environmentally sustainable tourism industry. J Travel Res 38(3): 239-245

5. Tour Operators' Initiative for Sustainable Tourism Development (2003) Sustainable tourism - The tour operators' contribution. Supported by the United Nations Environment Programme (UNEP), the United Nations Educational, Scientific and Cultural Organization (UNESCO) and the World Tourism Organization (WTO/OMT)

6. Leidner R (2003) The European Agenda 21 for Tourism. In: Engels B. (ed) Sustainable tourism and European policies: the European agenda 21 for tourism. Report on the NGO Workshop, Isle of Vilm, March 24-26, Publ. Federal Agency for Nature Conservation

7. Keenan M, Uyarra E (2002) Why regional foresight? An overview of theory and practice. Paper prepared for the STRATA - ETAN Expert Group Action on 'Mobilising the regional foresight potential for an enlarged European Union', European Commission Research DG - Directorate K, June, Brussels

8. UNWTO-UNEP (2012) Tourism in the green economy - background report. ISBN (UNWTO - printed version) 978-92-8441451-2, ISBN (UNEP printed and electronic version): 978-92807-3143-9

9. Logossah K, Fortuna M, Maupertuis M-A, Salmon J-M (2004) SIDS and tourism industry. In: Encontre P, Hein P (eds) Small island developing states in the global economy: selected issues. Chapter 10. UNCTAD Publication, Geneva

10. Spilanis J (2012) European island and political cohesion. Gutenberg, Athens (in Greek). ISBN 978-960-01-1544-4

11. Giannoni S, Maupetuis M-A (2007) Is tourism specialization sustainable for small island economy? A cyclical perspective. In: Matias A, Nijkamp P, Neto P (eds) Advances in modern tourism research. Physica-Verlag, Heidelberg, Germany. ISBN 978-3-7908-1717-1

12. Crusol J, Hein Ph, Vellas F (1989) L' Enjeu des Petites Economies Insulaires. Economica, ISBN-10: 2717815996, ISBN-13: 9782717815993

13. Chon KS, Olsen MD (1990) Applying the strategic management process in the management of tourist organizations. Tour Manag 11(3):206-213

14. Davos Declaration (2007) Climate change and tourism - responding to global challenges. 2nd international conference on climate change and tourism, United Nations World Tourism Organization (UNWTO), United Nations Environment Programme (UNEP), World Meteorological Organization (WMO), World Economic Forum (WEF) and the Swiss Government, Switzerland

15. UNEP-WTO (2008) Climate change and tourism - responding to global challenges. United Nations Environment Program, World Tourist Organization, ISBN: 978-92-844-1234-1 (UNWTO), ISBN: 978-92-807-2886-6 (UNEP)

16. UNWTO (2014) Tourism highlights. http://mkt.unwto.org/ publication/unwto-tourism-highlights-2014-edition. Accessed 22. 02.2014

17. Stratigea A, Papakonstantinou D, Giaoutzi M (2008) ICTs and tourism marketing for regional development. In: Coccosis $\mathrm{H}$, Psycharis J (eds) Regional analysis and policy - the Greek experience. Springer Physica-Verlag, Heidelberg, pp 315-333. ISBN 978-3-7908-2085-0

18. Stratigea A, Hatzichristos T (2011) Experiential marketing and local tourist development: a policy perspective. Int J Leis Tour Mark 2(4):274-294. doi:10.1504/IJLTM.2011.043786

19. Park D, Nam TJ, Shi CK (2006) Designing an immersive tour experience system for cultural tour sites. CHI 2006, Mondreal, Quebec, Canada, 22-27 April, ACM 1-59593-298-4/06/0004 
20. Katsoni V (2012) Tourism marketing segmentation and internet use in a trip characteristics strategic approach. 2nd International Conference on 'Entrepreneurship in the Hospitality Industry', 1112 October 2012, Cluj-Napoca, Romania

21. Katsoni V, Venetsanopoulou M (2013) Use of innovation systems for an effective tourism marketing development strategy. J Sci Technol 8(5):33-40, http://e-jst.teiath.gr/

22. Katsoni V (2014) The strategic role of virtual communities and social network sites on tourism destination marketing. J Sci Technol 9(5):107-117, http://e-jst.teiath.gr/

23. Stratigea A, Giaoutzi M, Nijkamp P (2006) The potential of virtual organizations in local tourist development. In: Giaoutzi M, Nijkamp P (eds) Tourism and regional development: new pathways. Ashgate, Aldershot, pp 51-70

24. Dwyer L, Edwards D, Mistilis N, Roman C, Scott N, Cooper C (2008) Megatrends underpinning tourism to 2020: analysis of key drivers for change. Sustainable Tourism Pty Ltd., Brooke Pickering

25. UNTWO (2002) Tourism market trends: world overview and tourism topics. World Tourism Organization, Madrid

26. Kavoura A, Katsoni V (2013) From e-business to c-commerce: collaboration and network creation for an e-marketing tourism strategy. Tourismos 8(3):113-128

27. COM (2010) 352 final Europe, the world's No 1 tourist destination - a new political framework for tourism in Europe. European Commission, Communication from the Commission to the European Parliament, the Council, the European Economic and Social Committee and the Committee of the Regions, Brussels, 30.6.2010

28. COM (2012) 494 final Blue growth opportunities for marine and maritime sustainable growth. European Commission, Communication from the Commission to the European Parliament, the Council, the European Economic and Social Committee and the Committee of the Regions, Brussels, 13.9.2012

29. Somarakis G, Stratigea A (2014) Public involvement in taking legislative action as to the spatial development of the tourist sector in Greece - the 'OpenGov' platform experience. Future Internet 6(4): 735-759. doi:10.3390/fi6040735

30. Panagiotopoulou M, Stratigea A (2014) A participatory methodological framework for paving alternative local tourist development paths - the case of Sterea Ellada region. Eur J Futur Res 2(44):1-15. doi:10.1007/s40309-014-0044-7

31. Special Framework for Spatial Planning and Sustainable Development for Tourism (2009) Official Journal of the Greek Government, 11th June, pp. 14345-14364 (in Greek)

32. Padgett $D$, Allen $D$ (1997) Communicating experiences: a narrative approach to creating service brand image. J Advert XXVI(4):49-62

33. http://el.wikipedia.org/ - The Heptanese islands - Lefkada

34. http://www.biodiversity.gr/ - NATURA 2000 zones in Lefkada island

35. Katopodi E (2014) Planning a sustainable pattern of tourist development for the Lefkada island - a micro- and macro-approach. Diploma thesis, Dept. of Geography and Regional Planning, School of Rural and Surveying Engineering, National Technical University of Athens (NTUA), Athens (in Greek)

36. Hudson S, Ritchie B, Timur S (2004) Measuring destination competitiveness: an empirical study of Canadian ski resorts. J Tour Hosp Plan Dev 1(1):79-94

37. David F (2003) Strategic management: concepts and cases. Prentice Hall, New Jersey. ISBN 0-13-047912-8

38. Stokes FB, Wechler B (1995) State agencies' experiences with strategic planning: findings from a national survey. Public Adm Rev 55(2):159-168

39. Ruhanen L (2007) Destination competitiveness: meeting sustainability objectives through strategic planning. In: Matias A,
Nijkamp P, Neto P (eds) Advances in modern tourism. PhysicaVerlag, Heidelberg, pp 133-151. ISBN 978-9-7908-1717-1

40. Stratigea A, Giaoutzi M (2006) ICTs and local tourist development in peripheral regions. In: Giaoutzi M, Nijkamp P (eds) Tourism and regional development: new pathways. Ashgate, Aldershot, pp 8398

41. Stratigea A, Papadopoulou Ch-A (2013) Multicriteria evaluation in spatial planning: a participatory methodological approach. Territorio Italia, Land Administration, Cadastre, Real Estate, Agenzia del Territorio 1(2), pp 85-97 (English version), pp. 8799 (Italian version)

42. Cooper C (1995) Strategic planning for sustainable tourism: the case of the offshore islands of the UK. J Sustain Tour 3(4):191-209

43. Murphy PE (1994) Tourism and sustainable development. In: Theobald W (ed) Global tourism: the next decade. ButterworthHeinemann, Oxford, pp 274-290

44. Giaoutzi M, Dionelis C, Stratigea A (2008) Sustainable tourism, renewable energy and transportation. In: Girard LF, Nijkamp P (eds) Cultural tourism and sustainable local development. Ashgate, Aldershot, pp 109-128

45. Stratigea A (2011) ICTs for rural development: potential applications and barriers involved. NETCOM 25(3-4):179-204

46. Puglisi M (2001) The study of the futures: an overview of futures studies methodologies. In: Camarda D (ed) Interdependency between agriculture and urbanization: conflicts on sustainable use of soil water. Bari: CIHEAM. Options Méditerranéennes, Série A. Séminaires Méditerranéens, no. 44, pp. 439-463

47. Rhydderch A (2009) Scenario planning. Foresight horizon scanning centre, Government Office for Science

48. Sardar Z (2010) The namesake: futures; futures studies; futurology; futuristic; foresight - what's in a name? Futures 42:177-184

49. Lindgren M, Bandhold H (2003) Scenario planning: the link between future and strategy. Palgrave Macmillan, New York. ISBN 978-0-333-99317-0

50. Olsmats C, Kaivo-Oja J (2014) European packaging industry foresight study - identifying global drivers and driven packaging industry implications of the global megatrends. Eur J Futur Res 2(39):110. doi:10.1007/s40309-014-0039-4

51. Cornish E (2004) Futuring - the exploration of the future. World Future Society, Maryland. ISBN 0-930242-57-2

52. Jäger J, Rothman D, Anastasi C, Kartha S, van Notten P (2007) Scenario development and analysis. GEO Resource Book, A training manual on integrated environmental assessment and reporting, Training module 6, United Nations Environment Programme (UNEP), International Institute for Sustainable Development (IISD)

53. Simpson K (2001) Strategic planning and community involvement as contributors to sustainable tourism development. Curr Issues Tour 4(1):3-41

54. Munda G (1995) Multicriteria evaluation in a fuzzy environment theory and applications in ecological economics. Physica-Verlag, Heidelberg

55. Munda G (2006) A NAIADE based approach for sustainability benchmarking. Int J Environ Technol Manag 6(1-2):65-78

56. NAIADE (1996) Manual and tutorial. Joint Research Centre, EC, ISPRA Website, Institute for Systems, Informatics and Safety, Version 1.0. engl., Italy

57. Ritchie JR, Crouch GI (2000) The competitive destination: a sustainability perspective. Tour Manag 21:1-7

58. Faulkner HW (2003) Rejuvenating a maturing tourist destination: the case of the gold coast. In: Fredline L, Jago L, Cooper C (eds) Progressing tourist research - Bill Faulkner. Channel View Publications, Clevedon, pp 34-86 